\title{
CVD Coating of Oxide Particles for the Production of Novel Particle-Reinforced Iron-Based Metal Matrix Composites
}

\author{
Sebastian Brust, Arne Röttger, Werner Theisen \\ Lehrstuhl Werkstofftechnik, Ruhr-Universität Bochum, Bochum, Germany \\ Email: brust@wtech.rub.de,roettger@wtech.rub.de, theisen@wtech.rub.de
}

Received 26 February 2016; accepted 24 April 2016; published 27 April 2016

Copyright (C) 2016 by authors and Scientific Research Publishing Inc.

This work is licensed under the Creative Commons Attribution-NonCommercial International License (CC

BY-NC).

http://creativecommons.org/licenses/by-nc/4.0/

(c) (i) (9) Open Access

\begin{abstract}
This paper focuses on surface metallization of oxide particles by means of titanium nitride (TiN) thin films for the production of highly wear-resistant metal matrix composites (MMC) on Fe-base for wear protection applications. These powder-metallurgically produced materials consist of a metallic matrix with embedded oxide hard-particles such as alumina or zirconia. The poor wettability of these oxides by iron-base melts and the resulting weak bonding between the components lead to porous materials and weak tribomechanical properties, thus limiting the material's application range. To counteract such problems, this paper describes a processing route in which the oxide particles are pre-metallized by application of a thin TiN coating by means of chemical vapor deposition (CVD). This surface metallization should increase the wettability and bonding behavior between the ionically bonded particles and the iron-base alloy, which should improve the mechanical and tribological properties. Therefore, a CVD device for coating ceramic particles was constructed and is described in this paper. Furthermore, coatings deposited on the ceramic substrates were investigated by means of RBS, SEM and XRD. In addition, the feasibility of producing metal matrix composites (MMC) by admixing the TiN-coated oxide particles with a Fe-base alloy and their further densification by supersolidus liquid-phase sintering is demonstrated.
\end{abstract}

\section{Keywords}

Chemical Vapor Deposition, Particle Coating, Metallization, Metal Matrix Composites, Reactive Wetting

\section{Introduction}

Wear-resistant composite materials, namely metal matrix composites (MMC), are often used as the build-up material for the protection of wear-loaded machines and component parts. These composites contain added hard 
particles that increase the resistance against coarse abrasive wear. In contrast, the function of the metal matrix is to embed the hard particles and to provide sufficient toughness, thus counteracting crack formation in the case of impact loading. To achieve good force transmission from the hard particle to the metal matrix and to avoid premature breakout of the particles during wear attack, the matrix and particles must have good adhesion to each other [1].

Alumina $\left(\mathrm{Al}_{2} \mathrm{O}_{3}\right)$, zirconia $\left(\mathrm{ZrO}_{2}\right)$ and eutectic mixtures $(\mathrm{AlZrO})$ thereof can be mentioned as candidates to produce novel low-cost highly wear-resistant MMCs. Until now, the application of Fe-based MMCs with oxides as hard particles has been limited due to the weak bonding between the particles and the metal matrix, which leads to weak tribo-mechanical properties of the MMC. This behavior can be attributed to the high chemical stability of the oxides and the low solubility of oxygen in Ni and Fe melts [1]. Because of this, no chemical interaction between oxide particles and the steel matrix can be observed and the embedding behavior of the oxide particles in the Fe matrix is weak [2]. In addition, due to the predominantly ionic and covalent nature of ceramics, alumina and zirconia are insufficiently wetted by metal melts [3], thus leading to porous materials.

In case of ceramic-metal brazing, the technology of pre-metallization of the ceramic's surface with titanium to increase the wettability of the ceramic by the filler material and to improve the bonding strength of the joint is well known [4]-[6]. The metallization can be performed mechanically either by physical vapor deposition (PVD) or by chemical vapor deposition (CVD). During the joining process, titanium reacts with the ceramic to produce a thin reaction layer of titanium oxides and it dissolves in the filler alloy to form interfacial titanium-rich phases, which increases the bonding strength.

To produce highly wear-resistant MMCs, the idea of pre-metallization to increase the wettability and the bonding strength of metal/ceramic interfaces is used by coating the surface of the hard particles. Winkelmann et al. [7] demonstrated that titanium-coated AlZrO particles can be used to produce particle-reinforced Fe-based MMCs via InduClad processing [8]. Nevertheless, the filling aspect ratio of PVD coatings is much lower compared to CVD coatings. High aspect ratios make CVD a promising technique for thin film coatings of particle beds. In addition, CVD coatings generally have better adhesion to the substrate than PVD coatings, which can be attributed to higher processing temperatures, promoting diffusion processes at the respective interfaces [9] [10]. Since deposition of pure metals by CVD techniques is complicated, titanium nitride could be an interesting material for such transfer layers because it has some rather metallic properties that lead to better wettability by metal melts than alumina and zirconia [3] [11]. Furthermore, deposition of TiN thin films by CVD is a well-investigated and a controllable process [12]. Jouanny-Trésy et al. [13] have shown that such a TiN coating can significantly increase the wettability of alumina particles during liquid-phase sintering of M3/2 high-speed steel with addition of alumina and $\mathrm{Cu}_{3} \mathrm{P}$ particles. The coated particles are wetted by the $\mathrm{M}_{3} \mathrm{P}$-type phosphide phase, resulting in lower porosity as well as enhanced cohesion between the particles and the matrix. This improves the wear resistance compared to composites with uncoated alumina particles.

To achieve homogenous TiN coatings on the particle surfaces, particle rearrangement during the CVD process is required. On the one hand, this is due to temperature gradients inside the particle bed. On the other hand, the reaction of precursors during the flow through the particle bed leads to consumption of precursors and generation of byproducts. This in turn causes different gas mixture at different points in the particle bed. Furthermore, particle/particle and particle/wall contact points can result in uncoated surface areas and thin film growth can provoke particle agglomeration. These problems can be counteracted by rearrangement of the particles during the coating process by means of fluidized bed chemical vapor deposition (FBCVD) [14].

In this paper, a CVD device for particle coating on the laboratory scale is presented and the coatings of rearranged and not rearranged oxide particle fillings are compared with regard to the microstructure and thickness of the coating. Since analysis of particle coatings is unpractical, the same set of parameters is used to coat a planar reference substrate, which allows investigation of the coating's properties. Thus, the presented CVD device gives the possibility to investigate the effect of the substrate's morphology (planar substrate/particle bed) and particle rearrangement during the coating process. Moreover, it is also shown that these coatings improve the wetting and substance-to-substance bonding between the oxide particles and an iron-based hard alloy by reactive wetting after densification of the material by means of supersolidus liquid-phase sintering (SLPS).

\section{Experimental}

\subsection{CVD Device for Particle Coating}

To fulfill the requirement of high aspect ratios of the coating, low-pressure chemical vapor deposition (LPCVD) 
was chosen as the deposition technique. The low pressure increases the diffusivity in the gas phase and thus allows gas exchange of precursors and byproducts in the particle bed [10] [14]. Titanium tetrachloride $\left(\mathrm{TiCl}_{4}\right)$ and ammonia $\left(\mathrm{NH}_{3}\right)$ were selected as precursors and nitrogen $\left(\mathrm{N}_{2}\right)$ as the carrier gas since this system has been used for many years to deposit titanium nitride thin films and the chemicals are readily available in industrial-scale amounts. The reaction can be expressed in simple terms by Equation (1) [12].

$$
6 \mathrm{TiCl}_{4}+8 \mathrm{NH}_{3} \rightarrow 6 \mathrm{TiN}+\mathrm{N}_{2}+24 \mathrm{HCl}
$$

To achieve homogenous coatings on the particle surfaces, the reactor tube is mounted vertically and the filling can be fluidized by the gas flow, which results in rearrangement of the particles. A hot wall reactor consisting of a tube furnace guarantees a homogenous temperature distribution within the particle bed.

Since thin film analysis on planar substrates is easier to perform than on particulate substrates, a second parallel reactor designed for planar substrates was constructed to achieve similar deposition conditions on these substrates. In addition, this reactor enables deposition of coatings on fixed particle beds and hence allows us to analyze the effect of particle redistribution on the coatings. For this purpose, a second reactor is mounted horizontally. Figure 1 shows a schematic diagram of the overall CVD system. Both reactors use the same gas supply and vacuum pump system.

The gas flow of ammonia $\left(\mathrm{NH}_{3}\right)$ and nitrogen $\left(\mathrm{N}_{2}\right)$ is regulated by mass flow controllers (MFC) from MKS Instruments Deutschland $\mathrm{GmbH}$. Titanium tetrachloride $\left(\mathrm{TiCl}_{4}\right)$ is evaporated in a bubbler. The temperature at the bubbler is controlled by heating cables. To avoid unwanted reactions of $\mathrm{NH}_{3}$ and $\mathrm{TiCl}_{4}$ before they enter the reactor, the gases are separated by a pipe system until they reach the reaction chamber. In the case of the horizontal reactor, this is achieved using a stainless steel tube for $\mathrm{NH}_{3}$ that is located inside the glass tube which feeds the gas mixture of nitrogen and $\mathrm{TiCl}_{4}$ (see Figure 2). The reactor itself consists of a silica glass tube with an inner diameter of $32 \mathrm{~mm}$.

In the case of the vertical reactor, the gases are fed from two different directions (see Figure 3). A flow of nitrogen gas from the bottom is necessary to fluidize the particle bed. The upper tube feeds ammonia gas and also contains a thermocouple to measure the temperature inside the particle bed. At the end of the tube, a nozzle with 8 holes having a diameter of $0.2 \mathrm{~mm}$ is installed to prevent particles blocking the nozzle. The tube arrangement is designed to minimize clogging of the porous silica glass frit (pore size $100-160 \mu \mathrm{m}$ ) on which the particle bed is placed. The pore size is a compromise for the following requirements: to prevent particles falling downwards, to maximize the gas flow, to prevent a strong decrease in pressure, and to minimize clogging due to deposition of reaction products in the frit. The reactor tube is also made of silica glass (inner diameter $32 \mathrm{~mm}$ ). Downstream of each reactor is a cooling trap immersed in liquid nitrogen. The vacuum is maintained by a rotary

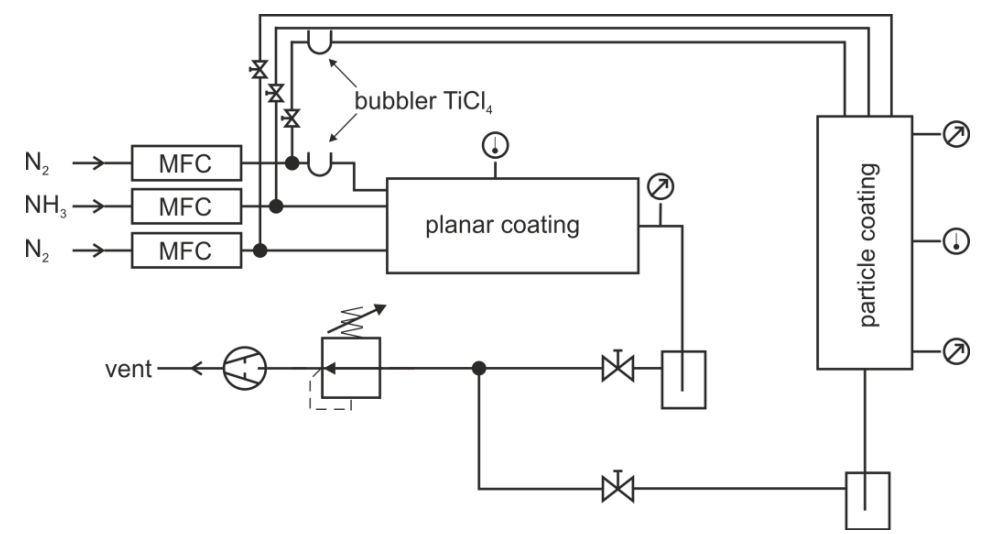

Figure 1. Schematic diagram of the CVD system.

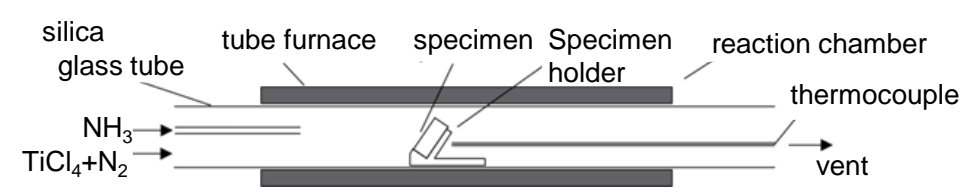

Figure 2. Schematic diagram of the horizontal reactor. 


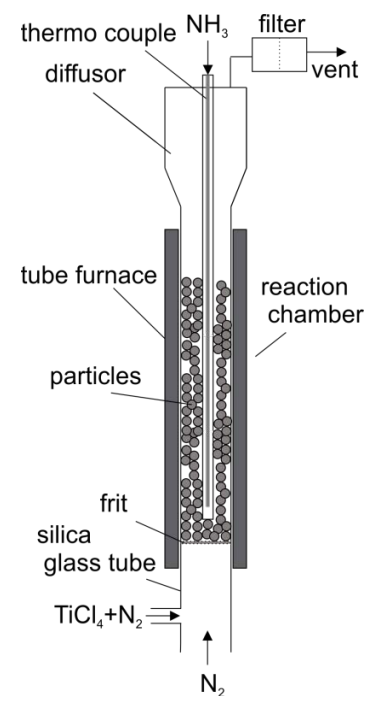

Figure 3. Schematic diagram of the vertical reactor.

vane pump. The pressure is controlled by a manual dosing valve and a capacitive pressure cell.

\subsection{Methods and Materials}

Titanium nitride was deposited on yttria-stabilized (5.4 mass-\%) zirconia (YTZP), with an edge length of $18 \mathrm{~mm}$ and a height of $8 \mathrm{~mm}$, purchased from CoorsTek Inc., USA. The selected hard particles were NorZon NV 1610 (AlZrO, grit size F24) from Saint-Gobain Ceramic Materials GmbH, Germany. The ceramic materials were cleaned in an ultrasonic bath for $10 \mathrm{~min}$ in acetone and $10 \mathrm{~min}$ in ethanol and subsequently dried before processing via CVD or sintering. The MMCs were produced from gas-atomized steel powder X210CrNiBMo10-4-2-2 (referred to as X210).

The coatings were deposited in the above-mentioned self-built CVD device with a reactor temperature of $800^{\circ} \mathrm{C}$ and a constant gas mixture of $100 \mathrm{sccm} \mathrm{N}, 60 \mathrm{sccm} \mathrm{NH}$, and approx. $35 \mathrm{sccm} \mathrm{TiCl}$. The pressure varied depending on the used reactor: from 12 - 15 mbar (YTZP_hor, horizontal reactor), 60 - 80 mbar (AlZrO_hor, horizontal reactor without fluidization), and 20 - 35 mbar (AlZrO_ver, vertical reactor with fluidization). The coatings were produced within $60 \mathrm{~min}$. Fluidization was performed every $10 \mathrm{~min}$ for $20 \mathrm{~s}$ with a gas flow of about $4 \mathrm{l} / \mathrm{min} \mathrm{N}_{2}$. An overview of the sample labeling of the deposition experiments is given in Table 1 .

In the following, MMCs were produced by mixing coated or uncoated AlZrO particles and steel powder X210 in a Turbula mixer for $30 \mathrm{~min}$. Furthermore, mixtures were subsequently densified by supersolidus liquid-phase sintering (SLPS) at a temperature of $1190^{\circ} \mathrm{C}$ within $30 \mathrm{~min}$ in a vacuum $\left(1 \times 10^{-2} \mathrm{mbar}\right)$. The heating rate was set to $10 \mathrm{~K} / \mathrm{min}$, and the samples were furnace-cooled in a maintained vacuum. Table 2 shows the sample labeling for the produced MMCs.

All samples for microstructural and chemical analyses were cut and prepared in accordance with standard metallographic procedures and investigated in a Teskan MIRA3 scanning electron microscope (SEM) in the backscatter mode. In addition, the chemical composition of individual microstructural constituents was investigated by means of energy dispersive X-ray spectroscopy (EDS) using an Oxford X $\operatorname{Max}^{\mathrm{N}}$ system. The acceleration voltage was set to $15 \mathrm{keV}$ and the working distance to $15 \mathrm{~mm}$. X-ray diffraction (XRD) measurements were performed using a Bruker D8-Advanced with a Bragg-Brentano arrangement and $\mathrm{Cu}-\mathrm{K} \alpha$ radiation. Diffractograms were evaluated in a $2 \Theta$-arrangement of $25^{\circ}$ to $80^{\circ}$ with an acceleration voltage of $40 \mathrm{kV}$ and a heating current of $40 \mathrm{~mA}$. During testing, the specimen was rotated to prevent influence of texture.

The chemical composition of the coating on the planar substrate was determined by Rutherford backscattering spectrometry (RBS) and nuclear reaction analysis (NRA) at RUBION, Ruhr-Universität Bochum. RBS was performed at the Dynamitron-Tandem accelerator with $2 \mathrm{MeV} \mathrm{He}^{+}$-ion beam. The beam intensity was about 40 $\mathrm{nA}$ and tilted $7^{\circ}$ to the sample surface. A silicon surface barrier detector with an energy resolution of $16 \mathrm{keV}$ was placed at an angle of $160^{\circ}$ with respect to the beam axis. NRA was carried out using a $1 \mathrm{MeV} 2 \mathrm{H}^{+}$-ion beam with a typical beam current of $40 \mathrm{nA}$ in an area of approx. $1 \mathrm{~mm}$ in diameter. The collected beam charge for one 
Table 1. Overview of sample labeling of thin film deposition experiments.

\begin{tabular}{ccccc}
\hline Sample label & Substrate material & Coating material & CVD reactor & Coloration \\
\hline YTZP_hor & YTZP & TiN & Horizontal & Gold \\
AlZrO_hor_black & AlZrO & TiN & Horizontal & Black \\
AlZrO_hor_gold & AlZrO & TiN & Vertical & Gold \\
AlZrO_ver_gold & Gold \\
\hline
\end{tabular}

Table 2. Overview of sample labeling of MMCs.

\begin{tabular}{ccc} 
Sample label & Hard particle & Matrix material \\
\hline X210_AlZrO & AlZrO & X210CrNiBMo10-4-3-3 \\
X210_AlZrO_TiN & AlZrO_ver_gold & X210CrNiBMo10-4-3-3 \\
\hline
\end{tabular}

sample was about $40 \mu \mathrm{C}$. The samples were tilted by $45^{\circ}$. Emerging protons from nuclear reactions with light elements were detected below an angle of $135^{\circ}$ with respect to the beam axis. The detector was shielded by a 6 $\mu \mathrm{m} \mathrm{Ni}$ foil to filter elastically scattered deuterium ions, and it covered a solid angle of $23 \mathrm{msrad}$. The spectra were subsequently fitted using SIMNRA code [15].

\section{Results and Discussion}

\subsection{TiN Coating on the YTZP Reference Substrate}

The YTZP_hor sample has a golden color, which is typical of titanium nitride coatings. Figure 4(a) shows a top view SEM image of the TiN coating on a planar YTZP substrate, which reveals a cauliflower-like surface texture. The coating exhibits good adherence and is about $3 \mu \mathrm{m}$ thick (Figure 4(b)). XRD analysis reveals a cubic TiN structure with preferential growth of the (200) orientation and a lattice parameter of $4.23 \AA$ (Figure 5) on tetragonal zirconia and small amounts of cubic yttria.

No interaction between the coating and the substrate was observed by scanning electron microscopy of the cross-section in as-deposited state, which is in agreement with the literature [16] and equilibrium thermodynamic calculations [17]. The chemical composition of the thin film was determined by combination of RBS and NRA experiments. Based on these experiments, the chemical composition of the coating was determined to be 51.3 at.-\% N, 45.4 at.-\% Ti, and 2.6 at.-\% O. The $\mathrm{C}$ and $\mathrm{Cl}$ contents are less than 1 at.-\%.

\subsection{TiN Coating on AlZrO Particles}

Figure 6(a) and Figure 6(b) shows SEM images of uncoated alumina-zirconia particles (AlZrO), which are composed of a eutectic structure of alumina (dark) and zirconia (bright). Coating of the particles in the horizontal reactor without fluidization leads to two different kinds of particle coatings in the macroscopic view: one has a shiny golden color. These particles were found in the front and upper part of the particle bed (AlZrO_hor_gold sample). The major part of the particles has a rather black appearance (AlZrO_hor_black sample). Figure 7 shows a schematic diagram of the experimental set-up and coloring in the particle bed when the AlZrO particles are coated in the horizontal reactor.

Microscopic analysis by SEM shows that two different regions coexist on the surface of the AlZrO_hor_black sample (Figure 8). In one region, the eutectic structure of alumina and zirconia can partly be seen. EDS analysis of this region (spectra S1) confirmed the existence of mainly Al, Zr, and O. In contrast, the covered regions have a cloudy appearance and mostly consist of Ti and N (spectra S2). Hence, the coating on these particles is discontinuous. In case of the AlZrO_hor_gold, the surface is completely covered by the TiN coating (Figure 9 and spectra S3). No cracks or flaking was observed. The morphology of the thin film on AlZrO_hor_gold is spiky. Due to the irregular particle shape, the coating thickness cannot be determined precisely in cross-sections, but it is less than $1 \mu \mathrm{m}$ on AlZrO_hor_black and ranges from 1 to $5 \mu \mathrm{m}$ on AlZrO_hor_gold.

XRD phase analysis of the coated particles was not possible due the irregular particle shape and the thin coating thickness. However, since the same set of parameters is used for coating the planar substrate as well as for the particles, the elements $\mathrm{Ti}$ and $\mathrm{N}$ are present on the particle surfaces, and the particles possess a shiny golden 

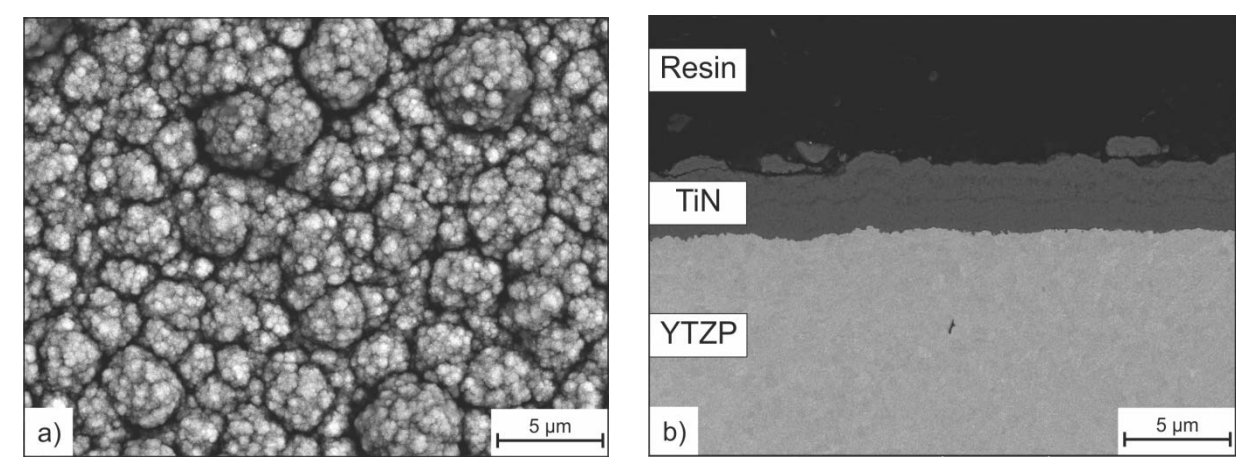

Figure 4. SEM image of a TiN coating on the YTZP_hor sample: (a) top view; (b) cross-section.

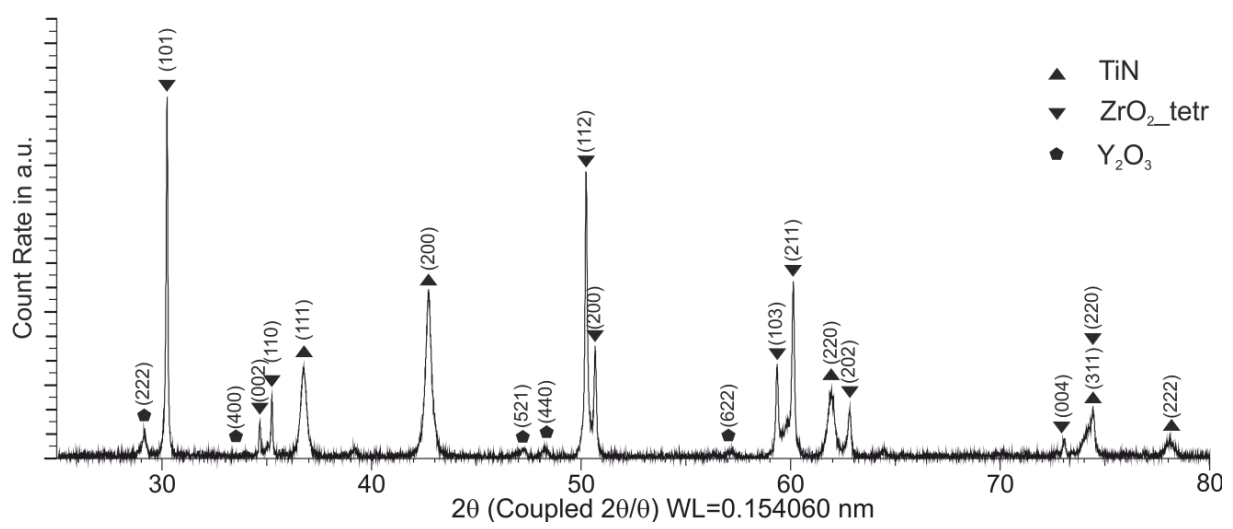

Figure 5. XRD pattern of the TiN coating on the YTZP_hor sample.
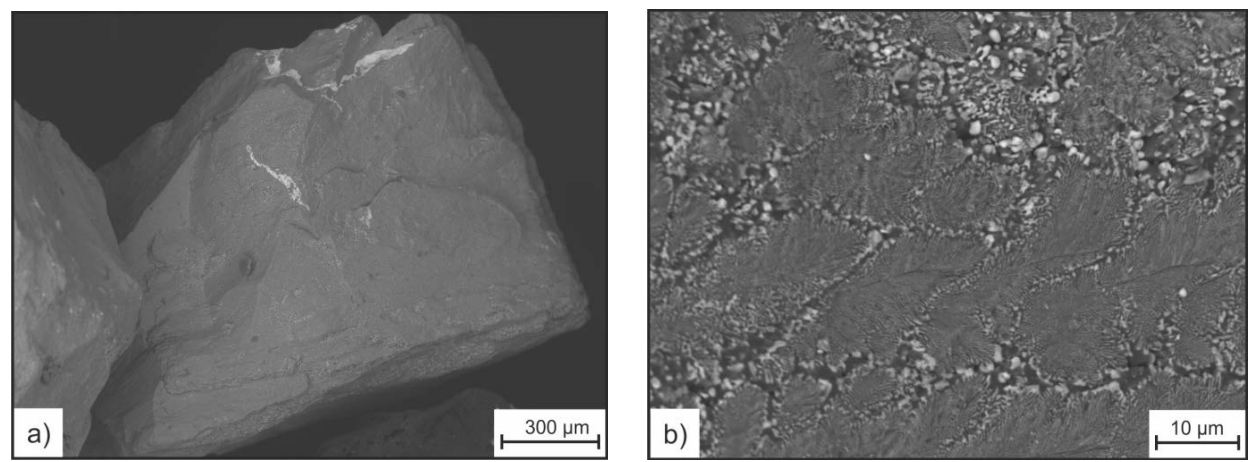

Figure 6. SEM images of an uncoated AlZrO particle.

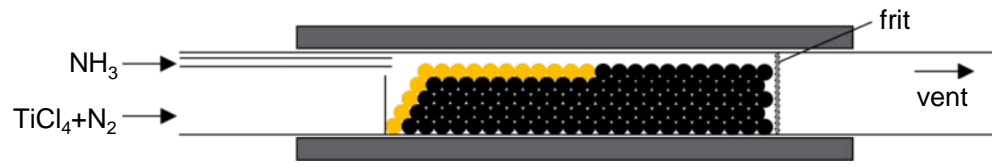

Figure 7. Schematic diagram of particles coated in horizontal reactor without fluidization.

color, it can be assumed that the phase in the coating is TiN. Regardless of the existence of TiN on every particle, the inhomogeneous coating on the particle is not sufficient for the production of MMCs, since this would lead to variations in particle/matrix cohesion, which in turn results in inhomogeneous material properties.

When using fluidization during the coating process, the most of the particle has a shiny golden colored coating (AlZrO_ver_gold sample). However, a few black colored particles are still observed. This leads to the assumption that the coating is not completely homogenous, but drastically improved in comparison to the 


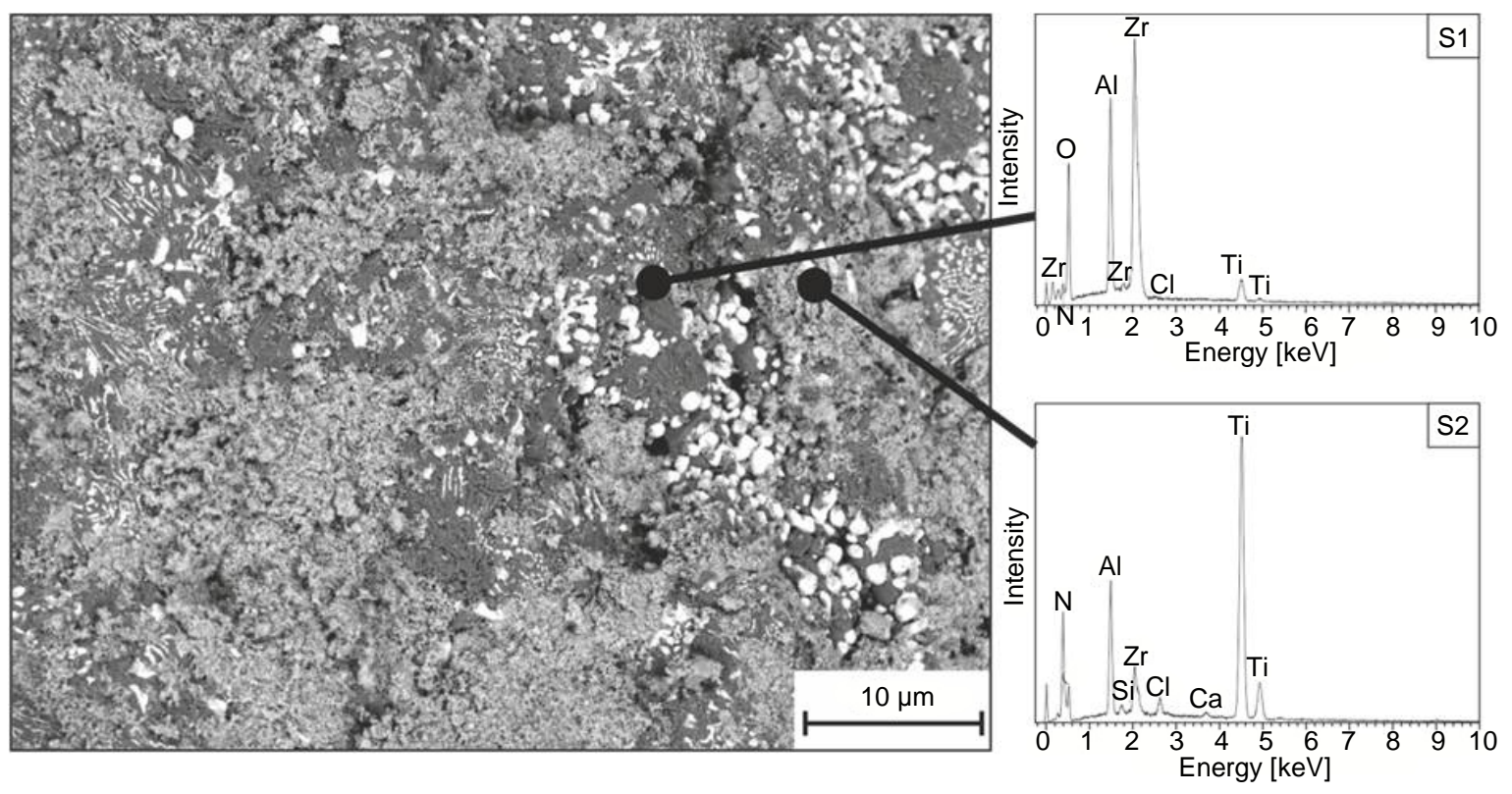

Figure 8. SEM image and EDS analysis of the AlZrO_hor_black sample, coated without fluidization.

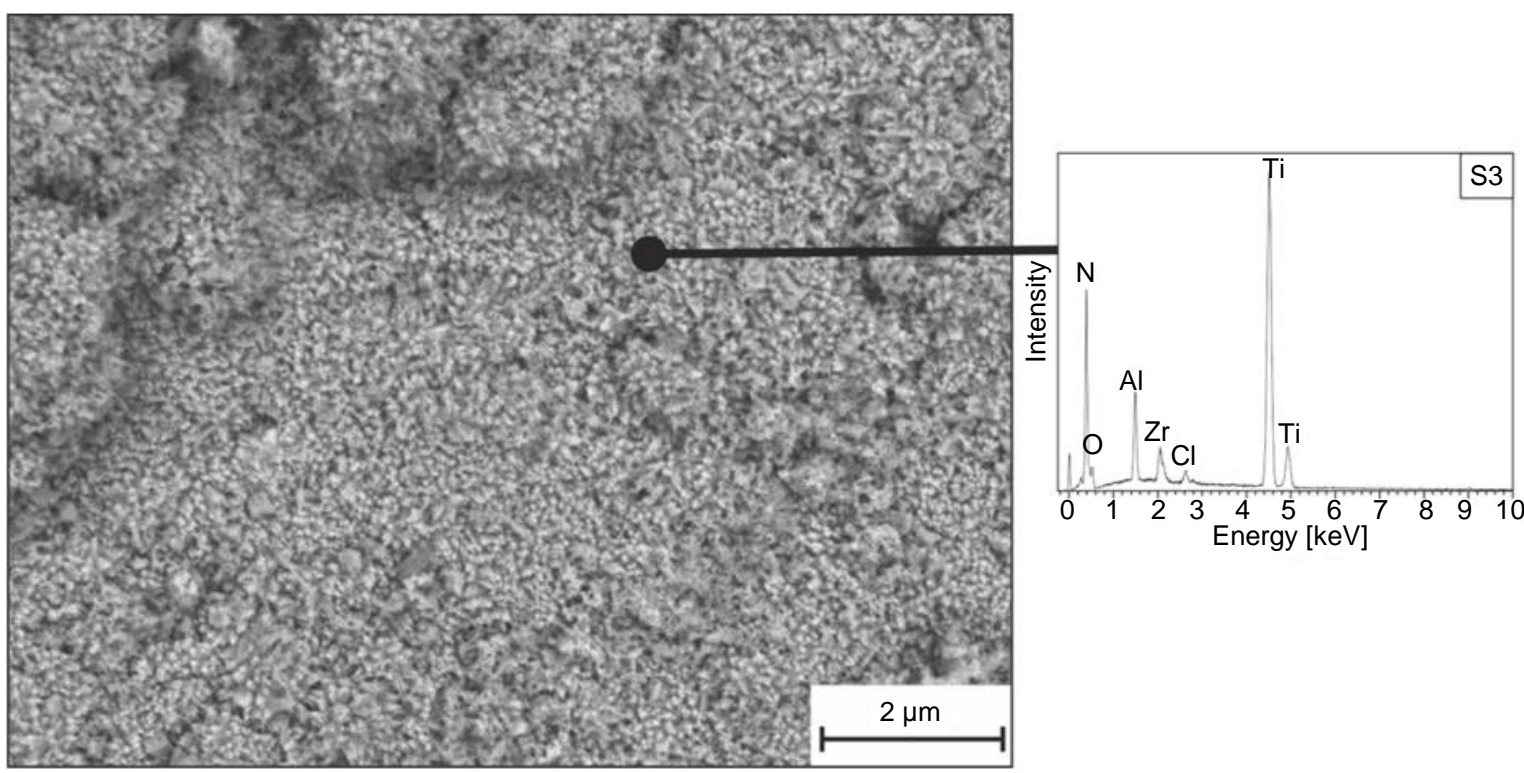

Figure 9. SEM image and EDS analysis of the AIZrO_hor_gold sample, coated without fluidization.

deposition experiments using the horizontal tube arrangement. The microstructure of the TiN coating on the golden colored particles is irregular and has a flakey shape (Figure 10(a)) and a thickness of up to $2 \mu \mathrm{m}$ (Figure 10(b)). The morphology of the black colored coated particles is similar to golden particles, but thinner $(<1 \mu \mathrm{m})$ and not dense. EDS analysis confirmed the presence of the elements Ti and $\mathrm{N}$ on the particle surfaces.

Differences in the coating thickness are a result of the surface area. The highest thickness that could be achieved was found on the planar YTZP_hor substrate, which has the lowest surface area. When coating particles, the coatings are thinner. This can be explained by the drastically increased surface area of the particle bed compared to the rectangular block specimen, which leads to the consumption of higher amounts of the precursor. This consumption of precursors also results in different coating thicknesses within one particle bed if no fluidization is used. In the front and upper regions of the particle bed, the precursors are almost unconsumed, which leads to a thick homogeneous coating on AlZrO_hor_gold particles, whereas particles inside the particle bed are 

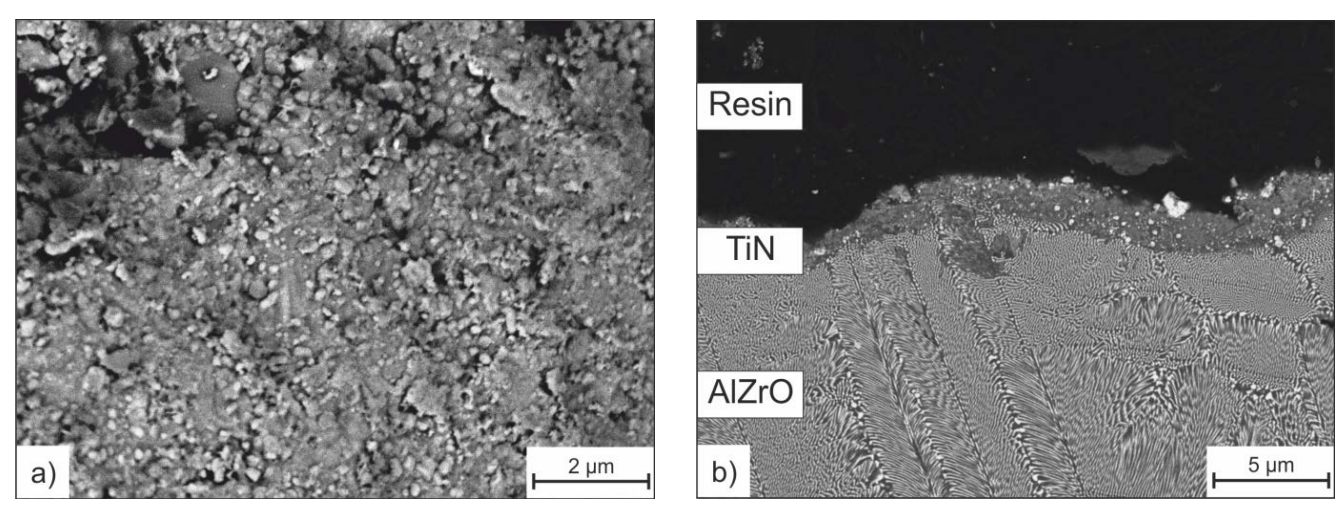

Figure 10. (a) SEM image of the AlZrO_ver_gold sample, coated with fluidization; (b) cross-section of the coating on AlZrO_ver_gold

exposed to a diluted gas mixture containing more byproducts, which leads to thin and inhomogeneous coatings (AlZrO_hor_black sample).

\subsection{Metal Matrix Composites}

The matrix material X210 is an ultrahigh boron, high carbon, hardfacing alloy that was characterized in detail by Röttger et al. [18]. The microstructure, densified by super solidus liquid-phase sintering (SLPS), consists of $\mathrm{M}_{2} \mathrm{~B}$ and $\mathrm{M}_{7} \mathrm{C}_{3}$ primary hard phases and Mo-rich $\left(\mathrm{M}_{3} \mathrm{~B}_{2}\right)$ and Fe-rich $\left(\mathrm{M}_{3}(\mathrm{C}, \mathrm{B})\right)$ eutectic hard phases embedded in a martensitic and austenitic microstructure. Its optimized sintering temperature was determined to be $1150^{\circ} \mathrm{C}$. In this paper, the sintering temperature was increased to $1190^{\circ} \mathrm{C}$ to produce enough liquid phase for wetting the added hard particles via SLPS [19].

When using uncoated AlZrO particles to produce MMCs (X210_AlZrO sample), the metal matrix exhibits low porosity, whereas the particle/matrix interface shows a high porosity (Figure 11(a) and Figure 11(b)). This can be attributed to poor wetting of the oxide ceramics alumina and zirconia by iron-based melts [3]. The wetting behavior changes when using TiN-coated AlZrO particles (X210_AlZrO_TiN sample). The coated particles are almost completely wetted by the X210 melt (Figure 11 (c) and Figure 11(d)), which leads to a low residual porosity at the particle/matrix interface. The difference in wetting can be explained by the differential electronic structure of $\mathrm{Al}_{2} \mathrm{O}_{3} / \mathrm{ZrO}_{2}$ and TiN. Although titanium nitride is a ceramic material with mainly ionic-to-covalent bonding characteristics [20], it also has aspects of metallic behavior such as good thermal and electrical conductivities [21]. This can be explained by the higher density of state (DOS) at the Fermi level, which enables exchange of electrons between the solid substrate and the liquid metal, and thus promotes wetting. This is in contrast to alumina and zirconia which do not show such metallic behavior. Nevertheless, wetting of TiN by metal melts is not good e.g. contact angles between $\mathrm{Cu}$ alloys and TiN are observed to be $>90^{\circ}$ [3].

However, to the authors' knowledge, there is no publication describing the wetting behavior of iron alloys on titanium nitride. Nevertheless, it is assumed by the authors that wetting is promoted by the reaction of alloying elements in the iron-based melt with the TiN coating to result in a reaction product that in turn is well-wetted. Higher magnification images of the interface of coated particle and metal matrix by SEM (Figure 11(d)) revealed a chemical interaction of the X210 melt with the TiN coating. At most parts of the interface, a phase with a bright appearance was found. This reactive wetting behavior was not observed for uncoated particles (Figure 11(b)). This leads to the assumption that the wetting is mainly non-reactive for alumina and zirconia, whereas the TiN-coating promotes reactive wetting by the X210 melt. This can be explained by the high thermodynamic stability of both alumina and zirconia [17], which means that these oxides cannot be dissociated by the molten iron alloy and thus no chemical interaction takes place. Thus, coating of oxides with TiN does not only promote wetting by iron alloys, but also leads to improved substance-to-substance bonds. However, the mechanical properties of the composite also depend on the properties of the reaction product at the interface [22] [23], which makes further analysis of these reaction products necessary.

Since knowledge of wetting and interaction of TiN by iron alloys is poor, future research by the authors will focus on this topic to gain a better understanding of the mechanisms taking place and to subsequently derive potential steel compositions with improved interaction and wetting on TiN. In addition, the interaction of TiN and 

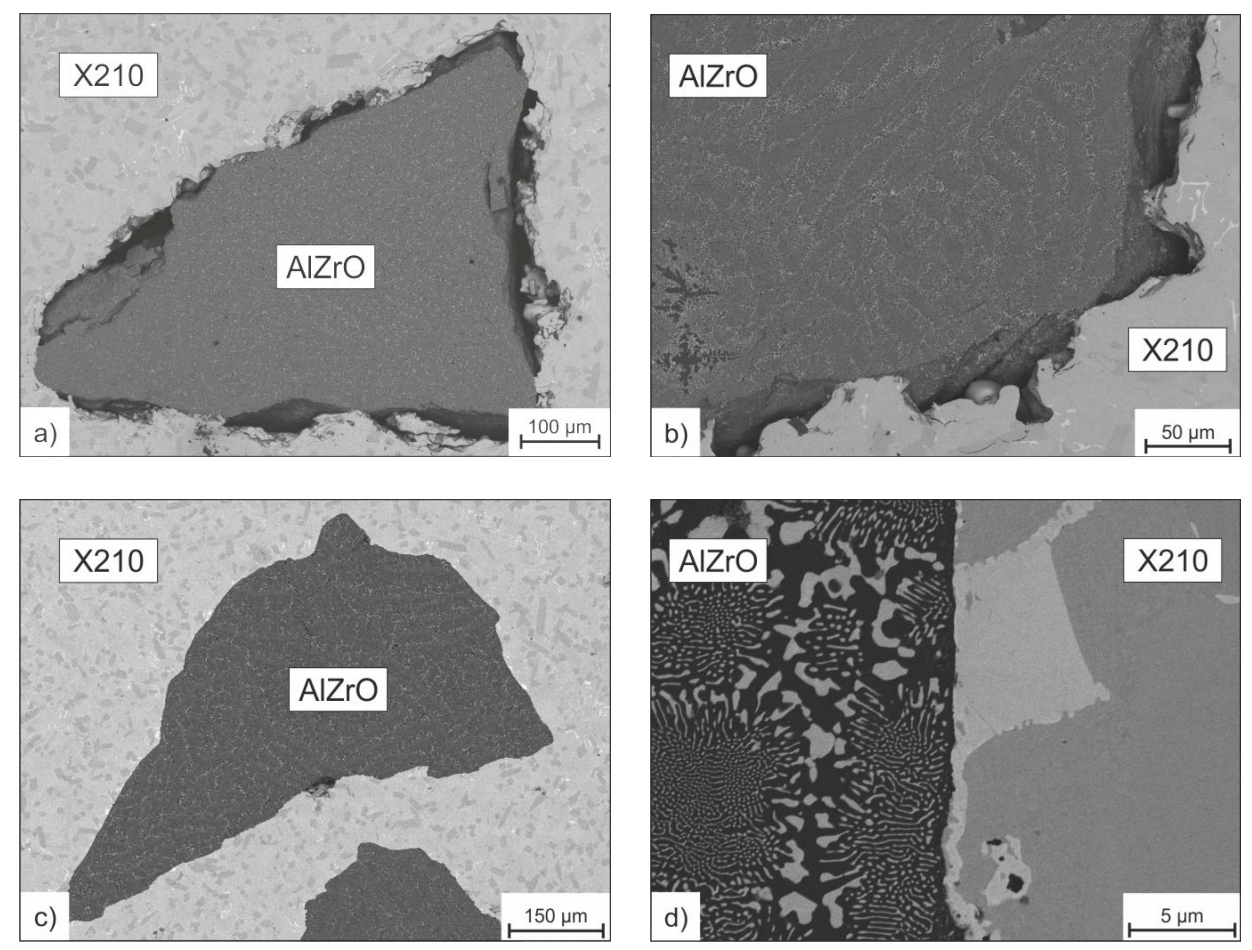

Figure 11. (a) (b) SEM images of X210_AlZrO; (c) (d) X210_AlZrO_TiN.

AlZrO particles during coating and processing could not be analyzed in detail due to the irregular particle shape. The interaction mechanism will also be analyzed in future work on planar substrates so that interaction in the entire system of AlZrO/TiN/steel will be understood in more detail. Concluding mechanical testing will analyze whether the presented pre-metallization scheme results in enhanced materials properties.

\section{Conclusion}

This work investigates the production route of novel wear-resistant particle-reinforced iron-based metal matrix composites (MMC) with coated oxide particles via supersolidus liquid-phase sintering (SLPS). For this purpose, a lab-scale CVD device was constructed to metallize the surface of hard particles by deposition of titanium nitride (TiN). It can also be used to coat planar substrates as well as particle beds. It is demonstrated that it is necessary to rearrange such particles during the coating process in order to generate homogenous coatings on the whole particle bed. The presented CVD device achieves this by discontinuous fluidization of the particle bed with a nitrogen gas flow. Furthermore, the feasibility of producing such MMCs with pre-metallized oxide particles is verified via SLPS. Coating the particle surface with TiN promotes wettability of the particles by molten iron alloys and enhances chemical interactions, thus improving bonding between the particles and the matrix.

\section{Acknowledgements}

The authors gratefully acknowledge the financial support from the Federal Ministry of Education and Research of Germany within the BMBF research project SubsTungs (ref. no. 03X3584). We also thank Dr. Detlef Rogalla from RUBION, Ruhr-Universität Bochum, for performing the RBS and NRA measurements.

\section{References}

[1] Berns, H. (1998) Hartlegierungen und Hartverbundwerkstoffe. Springer-Verlag, Berlin Heidelberg. http://dx.doi.org/10.1007/978-3-642-51505-7

[2] Pagounis, E. and Lindroos, V. (1998) Processing and Properties of Particulate Reinforced Steel Matrix Composites. Materials Science and Engineering: A, 246, 221-234. http://dx.doi.org/10.1016/S0921-5093(97)00710-7

[3] Eustathopoulos, N., Nicholas, M.G. and Drevet, B. (1999) Wettability at High Temperatures. Pergamon, Amsterdam, 
New York.

[4] Nascimento, R.M., Martinelli, A.E. and Buschinelli, A. (2003) Review Article: Recent Advances in Metal-Ceramic Brazing. Cerámica, 49, 178-198. http://dx.doi.org/10.1590/s0366-69132003000400002

[5] Lugscheider, E. and Tillmann, W. (1993) Methods for Brazing Ceramic and Metal-Ceramic Joints. Materials and Manufacturing Processes, 8, 219-238. http://dx.doi.org/10.1080/10426919308934826

[6] Walker, C.A. and Hodges, V.C. (2008) Comparing Metal-Ceramic Brazing Methods: The Advantages and Disadvantages of the Various Methods for Joining Metals to Ceramics Are Outlined. Welding Journal, 43-50.

[7] Winkelmann, R., Röttger, A. and Krause, C. (2013) Inductive Supported Coating. Heat Processing-International Magazine for Industrial Furnaces, Heat Treatment \& Equipment, No. 1, 61-65.

[8] Winkelmann, R., Smenda, J., Rank, T.W., Theisen, W., Röttger, A. and Weber, S. (2010) InduClad-verfahrens- und werkstofftechnische Grundlagen einer neuen Beschichtungstechnologie: Teil I: Verfahrenstechnische Grundlagen. Tagungsband GSI-SLV-Halle: 8. Fachtagung Verschleißschutz von Bauteilen durch Auftragschweißen; Halle (Saale).

[9] Brauer, G. (1963) Handbook of Preparative Inorganic Chemistry. 2nd Edition, Academic Press Inc., New York.

[10] Pierson, H.O. (1999) Handbook of Chemical Vapor Deposition: Principles, Technology, and Applications. 2nd Edition, Noyes Publications, New Jersey.

[11] Brust, S., Röttger, A. and Theisen, W. (2015) New Wear-Resistant Materials for Mining Applications. Proceedings of the 3rd International Conference on Stone and Concrete Machining (ICSCM), 3, 297-306.

[12] Kafizas, A., Carmalt, C.J. and Parkin, I.P. (2013) CVD and Precursor Chemistry of Transition Metal Nitrides. Coordination Chemistry Reviews, 257, 2073-2119. http://dx.doi.org/10.1016/j.ccr.2012.12.004

[13] Jouanny-Tresy, C., Vardavoulias, M. and Jeandin, M. (1995) Using Coated Ceramic Particles to Increase Wear Resistance in High-Speed Steels. JOM: Journal of the Minerals, Metals, and Materials Society, 47, 26-30.

[14] Vahlas, C., Caussat, B., Serp, P. and Angelopoulos, G.N. (2006) Principles and Applications of CVD Powder Technology. Materials Science and Engineering: R: Reports, 53, 1-72. http://dx.doi.org/10.1016/j.mser.2006.05.001

[15] Mayer, M. (1997) SIMNRA User’s Guide. Report IPP 9/113, Max-Planck-Institut für Plasmaphysik, Garching, Germany.

[16] Russell, W.C. and Padmanabhan, K.R. (1994) Modification of $\mathrm{Al}_{2} \mathrm{O}_{3}$-TiN Interface Chemistry to Improve Adhesion in CVD Coatings. Surface and Coatings Technology, 68-69, 221-228. http://dx.doi.org/10.1016/0257-8972(94)90164-3

[17] Barin, I. (1993) Thermochemical Data of Pure Substances. 2nd Edition, VCH Verlagsgesellschaft, Weinheim, Basel.

[18] Röttger, A., Weber, S. and Theisen, W. (2012) Supersolidus Liquid-Phase Sintering of Ultrahigh-Boron High-Carbon Steels for Wear-Protection Applications. Materials Science and Engineering: A, 532, 511-521.

[19] Weber, S. and Theisen, W. (2007) Sintering of High Wear Resistant Metal Matrix Composites. Advanced Engineering Materials, 9, 165-170. http://dx.doi.org/10.1002/adem.200600257

[20] Chen, K. and Kamran, S. (2013) Bonding Characteristics of TiC and TiN. Modeling and Numerical Simulation of Material Science, 3, 7-11. http://dx.doi.org/10.4236/mnsms.2013.31002

[21] Riedel, R. (2000) Handbook of Ceramic Hard Materials. Wiley-VCH, Weinheim. http://dx.doi.org/10.1002/9783527618217

[22] Howe, J.M. (1993) Bonding, Structure, and Properties of Metal/Ceramic Interfaces: Part 1 Chemical Bonding, Chemical Reaction, and Interfacial Structure. International Materials Reviews, 38, 223-256. http://dx.doi.org/10.1179/imr.1993.38.5.233

[23] Howe, J.M. (1993) Bonding, Structure, and Properties of Metal/Ceramic Interfaces: Part 2 Interface Fracture Behaviour and Property Measurement. International Materials Reviews, 38, 257-271. http://dx.doi.org/10.1179/imr.1993.38.5.257 